\title{
A SOCIOLOGIA ISRAELENSE E A CRISE DO CONSENSO SIONISTA*
}

\section{José Maurício Domingues}

\section{A crise}

Em meados dos anos de 1990, Shmuel Eisenstadt (1995) assinalava a "desintegração" do molde trabalhista-sionista, cujos elementos de nacionalismo primordialista e revolucionário fundamentaram a construção ideológica de Israel. Este processo, que se iniciara décadas antes, abriu um vazio ideológico, a que se somou um pluralismo crescente na sociedade israelense, levando a um reforço das identidades étnicas entre os próprios judeus e ao aumento da influência da religião. Associou-se a isso, ainda, a emigração de um milhão de judeus da antiga União

* Agradeço a Luis Roniger e a Mario Schnadzer o convite para uma estadia no Instituto de Estudos Avançados da Universidade Hebraica de Jerusalém e, ao primeiro, pela leitura de versão anterior deste trabalho.

Artigo recebido em agosto/2009

Aprovado em maio/2010
Soviética, com perspectivas bastante distintas das ondas de emigração anteriores. Esta crise do sionismo trabalhista tem um momento fundamental na chegada da direita, o partido Likud, ao poder em 1977. Baruch Kimmerling (2007a, pp. 1-3ss) chegaria a conclusões semelhantes: Israel enfrenta a decomposição da "hegemonia" trabalhista-sionista e, com forte pluralidade social emergindo, mergulha em "guerras culturais" desprovida de um modelo multicultural. Em contrapartida, mantêm-se os arraigados códigos culturais do "militarismo civil" e de um judaísmo genérico, bem como um Estado forte interna e externamente.

Por toda a sociedade israelense reverberam essas mudanças. Fortes confrontos têm tido lugar e novas identidades e problemas, emergido, com muitos intelectuais e jornalistas assumindo ou sendolhes atribuída, muitas vezes equivocamente, uma posição "pós-sionista", com flutuações em função das relações político-militares com a população pa- 
lestina. Destacou-se no debate intelectual sobre as origens e o destino de Israel o revisionismo histórico de Benny Morris e Ilan Pappée, que puseram em questão os momentos fundadores do Estado em 1948 e a "limpeza étnica" dos palestinos, expulsos em massa, o que estes chamam de al-Nakbah, a catástrofe, gerando o difícil problema dos refugiados e de seu desejo de retornar (com Morris no entanto defendendo hoje a inevitabilidade das expulsões, que deveriam, afirma, ter sido mais radicais) (Shapira e Penslar, 2002; Cypel, [2005] 2006). Articulando a resposta da direita, alguns denunciam esse pós-sionismo como ameaça ao Estado judeu, antepondo-lhe a continuação da expansão territorial do país, o apoio à religião, o reforço da educação judaica e a contínua glorificação do exército nacional (Hazony, 2000). Outros, no campo do trabalhismo tradicional, afirmam não haver nada de novo nisso: o pós-sionismo seria o tradicional "anti-sionismo" (Avneri, 2007).

Com esse pano de fundo, minha meta aqui é delinear aspectos-chave da evolução da sociologia israelense a partir dos anos de 1980. Alguns demandam uma agenda pós-sionista (Ram, 1995, pp. 205-207), outros abraçam a crítica, porém descartam o termo, por sua carga emocional e deficiências explicativas (Kimmerling, 2007a, p. 7), embora o argumento de que a "Escola de sociologia de Jerusalém", funcionalista e liderada por Eisenstadt, serviu à construção da nação e do Estado seja bastante generalizado. Buscando enfrentar as questóes que então emergem, reforçando por outro lado a crise da ideologia sionista, os sociólogos "críticos", vários marxistas, outros weberianos, trataram de vários temas: a integração forçada dos novos imigrantes; o poder crescente e concentrado do aparato trabalhista; as limitaçôes da democracia; a economia política e os problemas do corporativismo; a desigualdade social e a construção de uma verdadeira elite de poder, para quem a perspectiva socialista era mera ferramenta ideológica; o caráter europeu-oriental e exclusivista da ideologia sionista; a concentração exclusiva no yishuv (a sociedade judaica pré-Estado nas décadas de 1890-1940) e no Estado, com a aceitação dos mitos que os cercavam; a questão colonial na criação de Israel e sua reiteração contemporânea; a limpeza étnica dos palestinos e o expansionismo sionista; a militarização da sociedade; o status altamente subordinado das mulheres. Com seus estudos críticos sobre as "elites" israelenses nos anos de 1970 e 1980, Yonathan Shapiro (1984) teria sido uma inspiração para muitos desses novos autores, nem todos eles anti ou pós-sionistas. Agregue-se a isso que, segundo eles, somente a partir da ascensão do Likud ao poder o establishment acadêmico se fez mais crítico, ao perder suas conexōes privilegiadas (ver Ram, 1995; Kimmerling, 1992a, 2005).

Apenas indiretamente será essa a nossa questão. Mas não por acaso o período do que seria uma perspectiva integracionista e sionista na sociologia israelense espelha o que Bernstein (1978) chamou de "consenso ortodoxo" (positivista e funcionalista) na sociologia norte-americana. Essas teorizaçōes supunham um forte arcabouço normativo-integrativo e o deslocamento da contingência e do conflito na vida social, correspondendo à segunda fase da modernidade global, em que o Estado cumpriu grande papel organizador. $\mathrm{Na}$ fase seguinte, a terceira, atual, ocorre um aumento da complexidade e da heterogeneidade social (Domingues, [2000] 2003, 2009). Foi na segunda fase que se construiu Israel, culminando o nacionalismo sionista. Uma perspectiva integracionista e homogeneizante, bem como o nacionalismo metodológico que exclui os palestinos da análise, encaixava-se bem com o "giro modernizador" deslanchado pelo estatismo - mamlachtuit, ${ }^{1}$ diria Ben Gurion, o pai fundador de Israel. A sua crise corresponde àquela terceira fase, em que as diferenças se expandem para além do controle do Estado, o que se complica por ser Israel um ponto de encontro e choque entre o ocidente e o mundo árabe, e o judaico oriental, com fronteiras mal definidas e questóes étnicas e nacionais dramaticamente pendentes e aparentemente sem solução. ${ }^{2}$

Apenas uma resposta direta no campo acadêmico parece ter confrontado aquela bateria de críticas. Segundo Moshe Lissak (1996), sociólogo muito representativo do período anterior, o pósmodernismo guiava essas análises, cujos méritos às vezes reconhece, para em seguida negá-los. Os novos autores errariam ao descrever uma inexistente sociologia pró-establishment: seus objetivos eram políticos, não acadêmicos - a luta contra o sionismo e a imputação de falta histórica irreversí- 
vel, porquanto Israel tivesse "nascido em pecado". $\mathrm{Na}$ verdade muitos, inclusive ele mesmo, teriam tomado, argumentou, a questão árabe como central em suas análises. Lissak recusou validade à tese de que Israel teria origem em um processo colonial (o período pós-1967 sendo diferente). Objetividade seria a meta, o positivismo e o funcionalismo, instrumentos legítimos de conhecimento. Ele terminava com um comentário sobre a necessidade dos pais "fundadores" combinarem uma ciência livre de valores e de alta qualidade com seu caráter sionista, insinuando que seus oponentes defendiam causas externas ao Estado de Israel. Replicando, Gershon Shafir (1996b) criticou a fixação da escola antiga na "bolha judaica" e Michael Shalev (1996) fez a apologia da economia política, denunciando a insinuação de que haveria em jogo interesses alheios a Israel. Reconhecia, porém, que ataques demasiadamente pessoais haviam sido desferidos pela heterogênea sociologia crítica, o que contribuíra para o empobrecimento do debate. Ambos insistiram, ademais, no tema da colonização, que discutiremos adiante.

As singularidades de Israel, bastante reais, não podem ser reificadas e essencializadas, inclusive porque implicam importantes temáticas sociológicas e apresentam conceitos que podem ser de grande valia para teorizar a modernidade global e seus recortes nacionais. Veremos agora como Eisenstadt lidou com esses problemas e, em seguida, focalizaremos discussões acerca do nacionalismo e da democracia, da colonização na Palestina e da problemática (in) definição de fronteiras na região.

\section{Eisenstadt e as transformações da sociedade israelense}

Exatamente durante os anos de 1980, Eisenstadt alterava sua concepção teórica: afastando-se bastante do funcionalismo, enfatizava a "ação" das elites, a cultura e a contingência da vida social (Eisenstadt, 1990; Alexander, 1992). Além disso, como veremos, antecipava ou aceitava, de forma menos radical e mais discreta, parte das teses da sociologia crítica, sem prejuízo de seus fortes vínculos ideológicos com o programa sionista básico e uma perspectiva liberal-igualitarista, bem como de alguns silêncios e idealizações importantes.

Eisenstadt (1985, pp. 1-80) abre The transformation of Israeli society com uma discussão sobre a civilização judaica - que estudou extensamente em outros trabalhos e que está na base de sua teoria das civilizaçōes (ver Domingues, 2009). A civilização judaica emerge de uma Revolução Axial, em que se abriu um abismo entre a ordem transcendente e a mundana, com a necessidade de realizarem-se os imperativos da primeira na esfera da segunda. $\mathrm{Na}$ época do Segundo Templo seus elementos desenvolveram-se plenamente, desdobrando-se no curso de sua inserção no ambiente mais amplo e a partir de suas relações com as civilizações cristã e islâmica. Se ele define estas duas em termos puramente religiosos - evidenciando um dos problemas de sua teoria geral -, ao tratar da civilização judaica recusa essa abordagem e, embora acentue seu componente religioso, assevera que os judeus são um "povo", uma "nação" (Eisenstadt, 1985, p. 14). Não fora contudo possível, desde a queda do Segundo Templo, institucionalizar territorialmente a civilização judaica. Isso a levou a se desenvolver de forma heterogênea e descentrada, mas com identidade forte e contínua. Permanece sem justificativa a aplicação anacrônica aos judeus antigos e da idade média do conceito, nunca definido, de nação. Mas vale notar o destaque que, como bom aluno de Martin Buber, Eisenstadt empresta à relação entre particularismo e universalismo no judaísmo, nos quadros de uma competição com as outras religiōes monoteístas. Os judeus estão durante todo esse período sob o domínio de outros povos, sobretudo na "diáspora", mas a ambivalência e amiúde animosidade é mútua $\mathrm{e}$ constante, ameaçando identitariamente ambos os lados do conflito. Para eles, duas possibilidades se reiteram: seu fechamento particularista, num mundo que o Messias ainda não resgatou, com a manutenção de sua missão universal e aliança exclusiva com Deus, ou a abertura dessa mensagem profética em sua ausência ou ao menos na de um poder político que pusesse em prática as leis judaicas.

Eisenstadt (1985, pp. 84ss) sublinha o caráter de movimento revolucionário e nacionalista do sionismo - sem problematizar suas características, mas observando ali o ressurgimento da tensão 
entre particularismo e universalismo. $\mathrm{O}$ sionismo rejeitou a "emancipação" assimilacionista que se entrevia, embora com inúmeras dificuldades, com a Ilustração na Europa e reelaborou, de modo "totalista", visando concretizá-los criativamente, os temas da civilização judaica. Proporcionou grande energia aos colonos em Israel, mantendo forte ambivalência em relação à diáspora. A herança do parsonianismo cobra certo preço na seqüência do argumento, impondo o sionismo como um arcabouço, cuja institucionalização na Palestina deveria ser então investigada, conquanto novos problemas evidentemente surgissem. Apesar de reconhecer as razóes dos árabes para rejeitar a presença maciça dos judeus, a magnitude do conflito inevitável e mencionar as principais organizações judaicas para a colonização da Palestina, Eisenstadt não se detém no crucial tema da terra e sua monopolização por parte das organizaçôes sionistas para-estatais. Ele assinala, porém, a cegueira ou o descaso dos líderes sionistas em relação aos árabes e, mais ainda, enfatiza que desde sempre se apresentou no movimento sionista a perspectiva de colonização de toda a $\mathrm{Pa}$ lestina, tendo como pano de fundo Eretz Israel - a Terra de Israel - e não apenas o Estado de Israel, definido de variadas formas nas decisóes internacionais até 1948 ou mesmo 1967. Isso guarda relação direta com o peso da religião na reconstrução do judaísmo pelo sionismo, inclusive com um núcleo central das leis do Estado, relativas especialmente à vida familiar, sendo monopólio dos rabinos (Idem, pp. 42, 90 e 110-115). Quando ele assinala a questão dos refugiados palestinos, contenta-se com a versão, hoje insustentável, mas na época não questionada, de que eles simplesmente fugiram, abandonando suas possessões (Idem, pp. 137-139). O cume do elemento "patriótico" em seu ensaio é a celebração da "Guerra de Independência de 1948" e do estabelecimento de Israel, além de sua visão totalmente positiva das Forças de Defesa Israelenses (FDI) (Idem, pp. 161-162 e 182).

O sionismo foi um grande sucesso, a despeito de conflitos internos que quase levaram o yishuv à guerra civil (em especial entre os trabalhistas e os revisionistas, que incluíam tendências de extrema direita). ${ }^{3} \mathrm{O}$ "centro" hegemônico pioneiro e sua "elite revolucionária" acabaram por criar uma larga "periferia". A cultura trabalhista-sionista fora capaz de incluir e assimilar sucessivas levas de imigração (alyia) melhor que outros países, exceção feita, crescentemente, aos judeus "orientais", que já eram, na realidade, heterogêneos entre si e cuja relação com o sionismo era distante ou nula, além de serem mais pobres e com menos acesso ao "centro". Essa falta de integração resultou numa "questão étnica" interna e na estereotipada divisão entre asquenazins e sefaradins, ocidentais e orientais (Idem, pp. 117 120 , 186ss e 294-329), formulação na qual se discerne o problema mal resolvido da caracterização da "nação judaica". ${ }^{4}$ Pouco a pouco, a burocratização institucional, crescentes desigualdades sociais (já fortes mesmo no yishuv), a oligarquização dos aparelhos partidários, o clientelismo e a patronagem impuseram-se, ainda que simultaneamente o liberalismo político e o império da lei tenham se consolidado (Idem, pp. 234ss).

Embora sua análise da população árabe-israelense e da população dos territórios conquistados em 1967 de fato ocupe pouquíssimas páginas, Eisenstadt argumenta que aqueles obtiveram direitos civis e sociais reais se modernizavam e progrediam ao fim do governo militar que lhes fora imposto de 1948 a 1966. Uma nova identidade de minoria formava-se, sem total integração e sem que a relação entre o caráter judaico do Estado e o funcionamento da democracia fosse inteiramente equacionada (Idem, pp. 331ss e 370-380). Em compensação, além de "suspeita e cegueira" ante seus problemas, um forte paternalismo "semicolonial" delineouse. E, mais dramaticamente, a partir da guerra de 1967 não só o expansionismo e a expropriação de terras dos árabes foram retomados (tema que surge de repente na narrativa), como também o que fora apenas uma sociedade de colonos que buscava construir-se à parte dos anteriores habitantes da região (contra o desejo dos britânicos de consolidálos como uma classe alta colonial) tornou-se de fato uma sociedade "semicolonial", com a exploração dos trabalhadores árabes dos territórios conquistados em 1967. A ocupação desses territórios, que passaram a ser denominados por seus nomes bíblicos, Judea e Samaria, deixara de ser "temporária", sem que à população palestina fosse concedida cidadania (Idem, pp. 152-153, 332-333, 374-377, 
418-419 e 522-533). ${ }^{5}$ Se juntarmos a isto o papel que, segundo ele, a totalidade da Eretz Israel cumpre freqüentemente no imaginário sionista e israelense, não se pode dizer que seu diagnóstico fosse tranqüilizador.

Poderíamos seguir adiante e nos determos em outros temas deste longo livro: a decomposição do modelo trabalhista-sionista e a deterioração do sistema político, do império da lei e da civilidade, mas em compensação a expansão do protesto extraparlamentar. Some-se a isso uma concepção de segurança cada vez mais dura, além de central para a identidade coletiva, e guerras cuja legitimidade se mostrou cada vez mais duvidosa, com o exército assumindo um comportamento em relação aos árabes que, se a princípio era relativamente benigno, foi se tornando brutal, tudo isso resultando numa visão negativa de Israel internacionalmente. Ademais, esgotou-se a idéia de que a imigração completa para a Palestina levaria ao fim da diáspora (com os Estados Unidos tornando-se importante pólo do judaísmo). Isso tudo apontava para um "conservadorismo dinâmico", capaz de tratar de novos problemas sem, contudo, levar a uma mudança no núcleo cultural e institucional (Idem, pp. 416-417 e 424). ${ }^{6}$ Foi por essas razōes que Kimmerling (2007b) afirmou que o próprio Eisenstadt deveria ser visto na fronteira entre o "conservadorismo dinâmico" e uma perspectiva crítica.

Não é possível aqui a leitura detalhada de seu livro anterior, Israeli society (Eisensatdt, 1967), foco de violentos ataques. Eisenstadt assume obviamente o sionismo, trabalhando dentro da teoria da modernização e de um funcionalismo discreto. Sem dúvida, apresenta uma visão bastante idílica do yishuv e da formação do Estado, afirmando o descarte da opção colonial e apenas sobrevoando a questão da terra. Ademais, os fracassos na integração dos judeus orientais de múltiplas origens e mesmo sua situação de clara desigualdade seriam fruto sobretudo de seu tradicionalismo e autosegregação. Contudo, apontava a dominância dos asquenazins russos e poloneses, sua transformação em "elite dominante" que concentrava poder, status e benefícios materiais, bem como impulsionava "orientações monolíticas". Uma brecha abria-se entre ideologia e realidade, levando à "anomia" social.
Se a questão da imigração é tratada suavemente, as questôes interétnicas judaicas são abertamente reconhecidas, especialmente a "situação trágica" dos árabes: dominados militarmente, sua cidadania era incompleta, viam-se segregados e discriminados, com o desenvolvimento simultâneo do sionismo e do nacionalismo árabe, ao que se somava uma situação internacional explosiva, praticamente impedindo o desenvolvimento de uma identidade comum, que poderia ser politicamente importante e uma contribuição para uma identidade israelense mais "variada". Segundo ele, vale lembrar, a posição dos intelectuais teria se complicado em Israel. Sua inclinação à crítica contrapunha-se à "idolatria" do Estado que consolidara a nação, o que gerou um déficit de significado espiritual. A afirmação dos valores dos "pioneiros" era por onde a crítica podia se expressar (Eisenstadt, 1967, p. 388). Não seria essa uma autodescrição? Enfim, se algo de novo ocorreu em sua leitura ulterior da sociedade israelense foi certa acentuação do tom crítico, pois chegou a apontar a "queda da base revolucionária do sionismo" (Kimmerling, 2007b). Mas isso era "muito pouco, muito tarde" para as novas gerações e seus críticos.

\section{Uma "democracia étnica" em Israel?}

Se a dominância dos judeus em Israel é tamanha, como se vê claramente em Eisenstadt, como caracterizar sua democracia? Foi para enfrentar esta questão que um dos primeiros autores a estudar os árabes em Israel, Sammy Smooha (1997, 2002a, 2002 b e 2005), apresentou uma classificação de cinco tipos de democracia, vinculadas a uma visão particular das questôes étnicas e nacionais.

O primeiro seria a democracia liberal-abstrata, composta por indivíduos que desfrutam direitos iguais, tendo suas qualidades específicas restritas à vida privada e não havendo qualquer direito coletivo. O Estado se manteria neutro, sem recorrer a políticas de assimilação, regendo o país com uma noção de "patriotismo constitucional". Esse tipo de democracia seria mera suposição teórica, pois jamais existira. $\mathrm{O}$ segundo, mais comum no mundo ocidental, seria o tipo republicano liberal-democrá- 
tico, que efetivamente implicou a realização do tipo teórico anterior, com um Estado-nação cívico, em que vigoram direitos individuais, mas não coletivos. Mas aqui o Estado não seria neutro, optando pela homogeneização da sociedade em um quadro cultural específico e buscando políticas de assimilação. O terceiro tipo, multicultural, comportaria um Estado neutro, alheio à assimilação, a qual ocorreria de forma apenas mediana. Manter-se-ia a igualdade de direitos individuais, introduzindo direitos coletivos que não chegariam a ser legislados. Outra variante mais complexa de democracia seria a de tipo consocional, que incluiria um Estado binacional ou multinacional, com respeito à igualdade de direitos individuais, acompanhados, contudo, por direitos coletivos legislados. O Estado evidenciaria neutralidade ante os diversos grupos, descartando políticas de assimilação. Uma engenharia mais complicada preside a sua constituição política, incluindo distribuição proporcional de recursos, autonomia, poder compartilhado, possibilidade de veto, compromissos e consensos. ${ }^{7}$

O último caso é mais peculiar e demanda uma inovação conceitual: a "democracia étnica". Ela é similar à democracia liberal republicana na medida em que o Estado se põe ao lado da maioria, enquanto os outros tipos de Estado permanecem neutros nesse sentido. Mas não é cívica, pois nela os laços de sangue, a linguagem e a cultura comuns se mesclam com a reivindicação de um território, que seria propriedade exclusiva da nação étnica. $\mathrm{O}$ Estado promoveria a maioria cultural, social, econômica e politicamente, tratando as minorias como cidadãos de segunda classe, temidos por seus vínculos com "inimigos", excluindo-as do núcleo de poder político. Entretanto, são lhes concedidos direitos civis e políticos, é lhes permitido desenvolver-se para melhorar sua situação. O que há de mais contestável na democracia étnica é, obviamente, a violação flagrante da igualdade. Em geral esse tipo de democracia não sobrevive em sociedades profundamente divididas, encaminhando-se para a composição de uma democracia consocional. ${ }^{8}$ Nos anos anteriores a 1967, Israel seria o "arquétipo" desse tipo de democracia, mantendo-se como um Estado judeu que mistura etnicidade e religião - uma democracia de baixa qualidade, que poderia estender direitos indi- viduais e coletivos aos palestinos, sem que entrasse em pauta o consocionalismo.

Smooha rejeita o argumento sionista de que Israel seria similar aos países ocidentais, cuja democracia também teria base étnica. O nacionalismo étnico do sionismo tem raízes na Europa oriental, é intolerante e avesso a divisões, calcando-se em uma mistura de religião, nacionalidade e Estado (o que seria espelhado a esta altura pelo nacionalismo palestino-árabe). Nos países ocidentais os traços étnicos são secundários e, graças ao caráter cívico de seus sistemas políticos, as minorias não dão importância aos símbolos com os quais os árabes não podem se identificar em Israel. Trata-se de um "Estado judeu para os judeus", oficialmente sionista. Isso se expressa na Lei do Retorno, que em princípio confere cidadania imediata a qualquer judeu que "retorne" (os rabinos no fim das contas decidindo quem pode recebê-la). Em contrapartida, os árabes israelenses são considerados um risco para a segurança, o que implica sua exclusão do exército (organização crucial na definição da identidade e cidadania israelenses), discriminação permanente na vida cotidiana, constante vigilância pelo serviço secreto, em uma situação formal e permanentemente declarada como de emergência, com direitos podendo ser suspensos a qualquer momento. Para piorar, o país não tem uma constituição. Uma política de não-assimilação, de manutenção do status de maioria e minoria, é inquestionável. A integração dos árabes à democracia israelense segue, porém, se desenvolvendo, embora o nacionalismo palestino dentro do país também venha crescendo desde 1967, sem que isso leve à negação de Israel em si, mesmo que a idéia do caráter judaico seja permanentemente questionada. É possível imaginar, crê Smooha, que a situação se desenvolva rumo a uma "democracia étnica melhorada", mas a consolidação de uma variante mais "dura" não pode ser descartada.

O modelo de Smooha foi muito questionado. As'ad Ghanem, Nadim Rouhana e Oren Yiftachel (1998) negam o caráter democrático da "democracia étnica". O Estado de Israel possuiria "aspectos democráticos", não uma "estrutura democrática", pois a desigualdade aniquilaria essa possibilidade, para não mencionar a contínua "judeização" do 
país e os bloqueios à mobilização dos árabes. "Etnocracia" seria a melhor definição. Não faria sentido considerar a situação de Israel em termos apenas de suas fronteiras antes de 1967, pois essa "unidade de análise" já não existia, o que se agravou pelo envolvimento contínuo das organizaçōes sionistas externas na vida política do país. Esses elementos impediram a definição clara de um demos, com o conflito seguindo latente, não obstante melhorias incrementais. $\mathrm{Na}$ verdade, há muito em comum entre Smooha e seus críticos, mas estes, em virtude do esforço de Israel, não obstante as ambigüidades, em minar o princípio da cidadania universal, preferem enfatizar seus aspectos não democráticos, conquanto o país não seja uma "ditadura étnica" (como a Sérvia). Seriam factíveis movimentos de democratização de Israel e da Palestina como um todo, chegando-se eventualmente a um Estado binacional, a exemplo do processo vivido na Estônia, mas talvez pudesse ocorrer um recrudescimento de perspectivas nos moldes do que ocorreu em Sri Lanka (Yiftachel, 2006, cap. 1).

Por seu turno, Ruth Gavison (1999) busca escapar da formalidade do debate, de natureza efetivamente política. Israel seria uma nação co-extensiva com sua religião, cuja falta de base territorial teria levado a um esforço de justificação maior do que aquele realizado por outros nacionalismos; algo ainda mais necessário, na medida em que resolver esse problema implicava deslocamento e privaçōes para outra população. A autora propõe o raciocínio curioso de que os judeus não tinham direito à terra de Sion, mas sim de tentar estabelecer-se nela, ao passo que os palestinos, que enxergavam a que essa tentativa levaria, tinham o direito de impedir o assentamento em seu território, sem poder, entretanto, controlar a imigração judaica. As ondas de imigração e a emergência de uma comunidade judia que tinha como casa apenas a Palestina, bem como o sucesso na construção do Estado e uma renascença cultural, tornaram legítima a existência de Israel. Sem negar os elementos conflituosos da situação, Gavison vislumbra reformas do Estado israelense em uma direção liberal.

Shafir e Peled $(1998,2002)$ argumentam, porém, que os discursos democrático e etno-exclusionista se sustentam apenas por serem mediados por um discurso republicano baseado nas virtudes cívicas, originado no movimento trabalhista, base da coesão social e que apela aos judeus israelenses, sobretudo os homens, em favor do projeto colonial, legitimando um "regime de incorporação" estratificado à cidadania. O republicanismo vem declinando desde os anos de 1980, e paira no ar um discurso liberal sustentado pelos círculos dominantes asquenazins, cuja concretização é dificultada pelo peso do etnonacionalismo religioso militante de base popular. Complicando a situação, Ghanem e Rouhana, ambos israelense-palestinos, reconhecem que os árabes vivem em Israel um processo de democratização social e política, em parte sob a influência do Partido Comunista, conquanto o clá (hamula) ainda seja sua base social e a dominação das mulheres siga severa. Seus argumentos sugerem uma curiosa aceitação de aspectos da tradicional teoria da modernização (Rouana e Ghanem, [1993] 1999; Ghanem, 1998).

Nesse sentido, deparamo-nos com um dos temas mais espinhosos referentes a Israel, capaz de mobilizar ódios intensos, correndo-se o risco de ignorar certas sutilezas necessárias para um enquadramento produtivo. Qual seria de fato a relação entre etnicidade e nação? Eisenstadt, sempre tão sofisticado, simplesmente evitou a questão. Smooha, por sua vez, buscou uma definição mais adequada a esse respeito, baseada na caracterização do que seria, afinal, um grupo étnico. Vale notar que sua discussão também levanta indagaçôes acerca do conceito de república e sua relação com o nacionalismo. Enfim, pode-se se sugerir que a modernidade demanda alternativas individuais e coletivas, capazes de construir identidades mais concretas, para além do "reencaixe" proporcionado pela própria cidadania com seu universalismo abstrato. Se em parte o nacionalismo cumpre esse papel, sua variante que opera tal "reencaixe" mais concreto oscila de acordo com suas referências e conteúdos básicos. Nada há de necessário em sua constituição, ainda que memória e tradições não sejam de fácil transformação e que haja a possibilidade de um cancelamento da reflexividade pela via do dogmatismo (ver Domingues, 2002, caps. 1-2 e 6). Esta possibilidade, calcada no nacionalismo étnico europeu-oriental e no "primordialismo" construido pelo sionismo (não 
obstante seus óbvios elementos de plausibilidade, necessários para que tal construção tenha êxito) e por seus desdobramentos mais recentes, enlaça os judeus israelenses. Talvez isso também se imponha de certa forma aos palestinos, inspirados no sionismo por meio de uma mobilização étnica crescente em direção ao islamismo ainda que localismo nacionalista e pan-arabismo componham também sua identidade (ver Kimmerling e Migdal, 2003).

Será possível que Israel ultrapasse esse molde nacionalista étnico, rumo a um modelo mais inclusivo, ainda que por meio de uma evolução da "democracia étnica"? A constituição de um nacionalismo consocional ou mais cívico parece muito improvável, ao menos no momento. Em primeiro lugar por conta da importância da perspectiva sionista para a construção da identidade básica dos judeus israelenses e como ideologia do Estado, não obstante sua crise no plano utópico, ainda mais quando a situação volta a ser considerada ameaçadora, sem perspectivas de resolução pacífica. Além disso, constatam-se não só os interesses na distribuição de recursos que sistematicamente beneficiam os judeus em detrimento dos israelenses palestinos, mas também a deterioração, nos últimos anos, da relação com as minorias druzas e beduínas. Uma evolução benigna do nacionalismo dentro de Israel certamente contribuiria no processo de paz, mas seria também muito facilitada por ela, na medida em que os palestinos - "externa" e "internamente" não fossem percebidos como ameaça ou ao menos na medida em que a percepção de supostas ameaças fosse diminuindo. Mas essa evolução poderia deslocar interesses que a ela se ligam fortemente, embora as forças neoliberais do país a pudessem contemplar com simpatia, pois proporcionaria algum tipo de normalização internacional. Seja como for, a possibilidade de um endurecimento pela direita e pela religião, com elementos difusos de racismo, não pode ser descartada, mesmo porque atualmente é esta a possibilidade que comanda o país.

Nacionalismos étnicos, radicalismos religiosos e a falta de uma concepção multicultural criam enormes barreiras. Porém, cabe indagar se, no longo prazo, não seria possível ir além da obsessão com definiçôes de identidades puras (étnicas, religiosas ou políticas), aceitando suas diferenças e sobreposi- ção, qualquer que seja a solução estatal que venha a prevalecer no futuro. Não é fácil a esta altura visualizar dois Estados totalmente separados em espaço tão reduzido, com tanto potencial de violência, com questôes cruciais que dependem de coordenação mútua e com tantos valores sagrados atribuídos à terra por religiosos de diferentes linhas, além de tendências demográficas que implicam o aumento do peso relativo dos árabes palestinos nos próximos vinte anos. Tampouco parece possível imaginar que neste momento um só Estado, binacional, fosse viável, solução que teima em retornar (ao menos retoricamente) tanto quanto impulsiona resistências acerbas (Khalid, 2006; Ghanem, 2009; Morris, 2009). Contudo, uma efetiva dinâmica de abertura política, para além de uma concepção formal de democracia, pode-se esperar nos três "espaços" que compõem a região e se condicionam mutuamente o israelense, o palestino e o israelense-palestino para que essas questões voltem a ser tematizadas e para que a influência crescente dos militares na esfera política seja controlada (cf. Grinberg, 2009, especialmente caps. 2 e 11).

Questionam-se assim as fronteiras do país. Mais geralmente, impõe-se o problema metodológico de como incluir os palestinos - de "dentro" e de "fora" - para que se conceba Israel para além do nacionalismo metodológico, particularmente falho neste caso. Vejamos as duas principais versōes da teoria da colonização em Israel (Shafir e Kimmerling), que trataram precisamente desses temas, e da explosiva questão da terra, assim como os desdobramentos da discussão.

\section{A sociologia da colonização}

Não obstante suas críticas ao funcionalismo e ao elitismo, a teoria de Shafir é moderada em suas conclusōes. Os modelos coloniais estruturam-se em torno do controle da terra e da exploração dos nativos ou de mão-de-obra forçada e importada. "Colônias de povoamento" (pure settlement), com mão-deobra apenas de europeus brancos, e deslocamento ou destruição da população nativa, são outra possibilidade. A fronteira permanece em todos esses casos como problema e risco, tão maior quanto mais 
avançadas, densas e fixadas as populaçōes locais, com a contrapartida da relativa densidade populacional dos colonos e suas possibilidades concretas de ocupar a terra (teses inspiradas na obra de Turner, no mito da fronteira livre e do individualismo nos Estados Unidos). Em Israel duas possibilidades se impuseram em uma situação de parcos recursos naturais, densidade nativa razoável e inicialmente poucos colonos: a exploração das populações locais por fazendeiros judeus ou, em um segundo momento, o pagamento de melhores salários aos trabalhadores judeus da Europa oriental da segunda onda de imigração. Eles forçaram uma "bifurcação" do mercado de trabalho, excluindo os árabes em nome da economia judaica (vale lembrar que a entrada no país de judeus yemenitas para trabalhar com o mesmo nível de subsistência dos árabes logo fracassou). As fazendas coletivas (kibbutz) são o melhor exemplo da ideologia "coletivista" de enobrecimento do trabalho - a Organização Sionista Internacional subsidiava trabalhadores convertidos em colonos, garantindo-lhes terra, que inicialmente tinha de ser comprada (Shafir, 1996a, pp. 7-20ss).

Shafir reconhece que o sionismo começou como um nacionalismo europeu-oriental, mas que sua ideologia e a "hegemonia" do trabalhismo foram decorrentes das lutas no mercado de trabalho e da "colonização de povoamento separatista" que levaria ao exclusivismo judaico (1996a, p. 8). ${ }^{9}$ Ciente da baixa densidade demográfica e desprovida de tendência ao expansionismo, a liderança trabalhista evidenciava realismo político e disposição para estabelecer um compromisso com os árabes. Era legítima a aspiração por um Estado nacional, e talvez Israel só pudesse ter surgido dessa forma. O mercado fechado abriu, todavia, as portas para um exclusivismo expansionista mais amplo e formas extremas de nacionalismo territorial, de conseqüências catastróficas. Shafir enfatiza que a moralidade do empreendimento sempre dependera do reconhecimento da necessidade de fazer justiça à população árabe e, mobilizando Weber, demanda uma "ética da responsabilidade" capaz de dar conta das consequiências nefastas da colonização (Shafir, 1996a, pp. xi-xiv, 17-21 e 198-220). Ao menos retoricamente, o autor parece ter endurecido sua visão da colonização em publicações subseqüentes (cf. Shafir e Peled, 2002).
Anteriores às de Shafir, as teses de Kimmerling são mais radicais. Em um livro fascinante, mostra como se estabeleceu na Palestina uma sociedade de colonos em uma situação de "muito baixa fronteridade", isto é, poucas terras disponíveis para assentamento - ao contrário do que Turner descreve em relação aos Estados Unidos -, o que levou a estratégias coletivistas de ocupação antes que a um individualismo que tivesse um papel mais significativo (Kimmerling, 1983, pp. 1-8 e 144). Como Eisenstadt, ele afirma que a ideologia sionista era calcada em elementos religiosos - a "terra de Israel" apresentada como a única escolha possível - e que foram considerações dessa natureza, e não econômicas, que impulsionaram a colonização. Mas, ao contrário do que se divisava, havia habitantes na região, e a propriedade da terra, embora confusa muitas vezes, sobreposta ou incompreensível para os imigrantes, pertencia aos árabes (Idem, 1983, pp. 8ss; 2007a, p. 67). ${ }^{10}$

Kimmerling descreve uma atitude aberta e bem-intencionada da maioria dos imigrantes sionistas ante os árabes, e um desejo geral de convivência pacífica. Mas assinala também a astúcia de tratar a terra a ser comprada como mero bem econômico para, em seguida, transformá-la em patrimônio nacional. Os camponeses acabavam expulsos das terras e havia má vontade das lideranças árabes quanto à presença judaica maciça na regiāo, crescentemente compreensível para os sionistas mais argutos, pensassem eles em chegar a um acordo ou já vislumbrassem um confronto inevitável e áspero no fim da linha. No primeiro período da colonização, a única opção era a compra de terras, que não ultrapassou $7 \%$ do total. Assim, a presença física na terra ocupada e a defesa militar eram também necessárias, o que garantiu preponderância à esquerda (Idem, 1983, pp. 11ss, 79-83, 94, 104 e 106ss). A partir da Guerra de 1948, a conquista e a expropriação unilateral converteram-se no método principal de colonização, concomitantemente à "desarabização" do território, opção derivada da evolução dos próprios conflitos, implicando uma ampla "limpeza étnica” e a diáspora palestina (Idem,1983, cap. 5; 2008, p. xiii).

Em 1967 a alternativa expansionista - praticamente descartada havia duas décadas - apresentou- 
se novamente, levando à incorporação, malgrado o enorme problema que gerava, de grande população palestina. Gush Emunim, o movimento dos novos colonos, "crentes/fiéis", fez-se cada vez mais influente, bebendo nos elementos religiosos contidos na ideologia sionista e demandando com violência a ampliação das sempre indefinidas fronteiras de Israel. A margem ocidental do Rio Jordão foi sendo ocupada, em parte por política do governo, em parte pela criação de fatos consumados pelo movimento, que buscava substituir a imagem pioneira do kibbutzim, expressão da colonização trabalhista por antonomásia (Idem, 1983, cap. 6 e p. 223-4; também 2007a, pp. 110, 123 e 231). Isso levantou uma questão grave de legitimação, "existencial", para a sociedade israelense, quanto a seus direitos, e os dos árabes, sobre o território, tema sempre sensível para o sionismo trabalhista. Voltava à tona a questão mal resolvida das relações entre universalismo e particularismo na ideologia sionista - tratada de forma pragmática pelo trabalhismo, mas sem força política, levando o Likud, herdeiro do revisionismo, a enveredar resolutamente para uma visão particularista do mundo (Idem, 1983, p. 29 e cap. 7; também, 2007a, pp. 128-129). Até então Kimmerling (1983, p. 232) afirma o caráter democrático de Israel, "ao menos para os judeus", os árabes estando de fato submetidos a seu poder, o que posteriormente aguça a crítica do autor, sobretudo ao apontar o "militarismo cívico" israelense que, fruto do interminável conflito, gerava, com o controle do território, um regime de Herrenvolk, vigilância, controle e repressão em toda a Palestina. Uma obsessão com a segurança ramificava-se cultural e cognitivamente, tornando-se onipresente (Idem, [1992b] 2008)..$^{11}$

Ao passo que Eisenstadt enfatiza a questão cultural, para Kimmerling é a pulsão pela acumulação de território, advinda da colonização, portanto o poder, conjugado à cultura, que subjaz ao expansionismo israelense. Shafir, por sua vez, dá prioridade aos mecanismos econômicos e suas derivações. Mas no plano conceitual mais geral, de que maneira esses elementos se conjugariam e em que grau seriam reforçados em casos de conflitos como este entre coletividades? Importa aqui sublinhar que a tendência expansionista tem levado Israel a chocar- se com os árabes há um século, tornando-se talvez a última sociedade colonizadora do mundo. Os territórios ocupados, fundamentais para certas versões $\mathrm{da}$ identidade coletiva israelense, encontram-se em situação ambígua, nem dentro nem fora do Estado. Se Israel não os anexa formalmente, há um profundo envolvimento cotidiano com a população, sempre a favor dos colonos judeus, no que se refere à vigilância, à repressão e à regulamentação da terra, principalmente por meio das Forças de Defesa de Israel (FDI) (Kimmerling, 2007a), pp. 3, 81-85 e 185; Grinberg, 2009).

Isso vem gestando o que Yaftachel (2006, pp. 78-83) chama de "apartheid paulatino" (creeping apartheid), em que a segregação vaza para dentro das fronteiras formais do país (ver também Kimmerling, 2007a, p. 232). Assim, o tema resvala no sentido de legitimar a capacidade repressiva estatal em defender a nação de "ameaças existenciais", reiterar o sionismo e transformar os palestinos na figura do "outro ameaçador" da identidade nacional, que deve, portanto, ser submetido (Grinberg, 2009). A pseudo-solução imediata para o conflito foi a construção de uma barreira (muro) para evitar os terríveis e desesperados ataques suicidas palestinos. Obviamente, ela não resolve o problema de fundo e, ao garantir a anexação de várias partes da margem ocidental, na verdade agrava e dificulta uma possível solução futura, legitimando fatos consumados pelos colonos e gerando enormes problemas para os palestinos - separados de suas terras, empregos e familiares, submetidos a uma brutal vigilância militar e assassinatos, sobretudo de civis, humilhações e violência constantes, bem como a expropriação de terras e água, para não falar da trágica situação humanitária da Faixa de Gaza. Vale lembrar que o Likud fora contra a construção do muro, porquanto possa limitar a expansão territorial de Israel, que segue, temporariamente, no entanto, pelos mais engenhosos meios de opressão continuada.

\section{Palavras finais}

Não se trata de buscar uma conclusão para este artigo. Os textos analisados expõem diversas inter- 
pretações para a evolução da sociedade israelense, bem como sugerem idéias e conceitos de amplitude global, e até certo ponto falam por si. É importante notar o quanto esses debates são densos politicamente e que a própria descrição das posições em questão remete à construção do Estado israelense e à posição dos sociólogos no processo, gerando um inevitável ruído, muitas disputas semânticas e nem sempre precisão.

Há muitos problemas em Israel que são comuns a outros países (Eisenstadt, 1985, p. 401), ainda que com características peculiares. Ao lado da persistência de uma ideologia sionista, assistimos a uma pluralização das identidades. Ao lado da polarização política entre "McDonnald versus Jihad" (Tel Aviv versus Jerusalém, consumo e acomodação versus religião e confronto), aparecem a neoliberalização econômica e a globalização, com a queda do sindicalismo corporativo e o crescimento da desigualdade e da pobreza (Ram, 2008; Ben-Pora et al., 2008). Esses "giros modernizadores", projetos e opções que os diversos setores da sociedade israelense em suas vagas fronteiras estão construindo e realizando hoje resultam de embates e escolhas específicas, mas estão fortemente sobredeterminados pela permanência de um processo tardio de colonização. Como vimos, colonização e fronteiras, democracia, nacionalismo e etnicidade, republicanismo e liberalismo, pluralismo e homogeneidade, universalismo e particularismo são questôes que abarcam o cenário dramático da Palestina contemporânea. Não obstante a efetiva construção de um país avançado em muitas áreas, resultado de poderosas energias ativadas pelo sionismo, Israel não se sai bem np retrato de seus sociólogos, o qual certamente pioraria caso realizássemos uma análise mais detalhada do que ocorre hoje nos territórios ocupados ou supostamente desocupados (pois permanecem sob violenta vigilância militar). A desorganização intencional da "sociedade civil" palestina e da Autoridade Nacional Palestina (ANP) por parte de Israel, por meio de prisóes e ataques militares - com a ANP, por seu turno, cada vez mais inclinada a monopolizar os espaços políticos, construindo uma força policial em seu território -, bem como a emergência do islamismo radical (sobretudo na Faixa de Gaza e em outros campos de refugiados, mas também na margem ocidental), agrega mais um elemento explosivo e complicador ao cenário inicial do conflito (Kimmerling e Migdal, 2003, caps. 9-11).

Se os árabes, não sem boas razões, mantiveram desde o início uma visão de soma-zero em relação ao conflito estabelecido, visão que também foi aos poucos adotada pelos sionistas, a esta altura parece não haver alternativa que não superar tal perspectiva para que a paz seja alcançada (Kimmerling, 1983, pp. 94 e 219; Kimmerling e Migdal, 2003, caps. 10-11). Em que pese um horizonte tenso e nada auspicioso, a solução do conflito está em aberto e depende de como as diversas coletividades em choque encontrarão, ou não, os meios para superar os impasses e a brutalidade que as envolvem. Aqui vale retomar a frase indelével de Sartre: o que importa não é o que fizeram conosco, mas o que fazemos com o que fizeram conosco. $\mathrm{Na}$ Palestina, ou alhures, ninguém pode evitar fazer escolhas, individual ou coletivamente, as quais sempre incorrem em custos. Judeus e árabes encontram-se entrelaçados em um trágico destino comum, mas àqueles cabe hoje uma responsabilidade muito superior na abertura do espaço político e na aceitação de compromissos, assim como na adoção de uma concepção de mundo universalista em detrimento do particularismo que comanda a política "exterior" israelense, mercê de seus enormes ganhos históricos à custa do poder desigual que detêm em relação aos árabes. É improvável que o juízo final os venha a julgar. Mas a história certamente o fará.

\section{Notas}

1 Este conceito refere-se a um estatismo que subordinaria as organizações sionistas anteriores ao Estado judeu, no terreno militar e social, mas também do ponto de vista de uma economia em que ele teria grande peso, como de resto era bastante comum neste período internacionalmente.

2 Nesses debates a figura de Kimmerling é crucial. Se cedo tratou em seu doutorado da relação territorial entre judeus e palestinos - malgrado, conta-nos, resistências -, era parte da "Escola de Jerusalém" (caracterização que difundiu). Somente depois passou a criticar o establishment acadêmico, sem poupar muitos dos que propunham perspectivas alternativas. Prova- 
velmente o início, em 1987, da primeira intifada e a resposta israelense a ela pesaram nessa radicalização e em sua definição explícita do "conflito" como intrínseco à vida social, como em Simmel e Coser, sem prejuízo, ao contrário, do funcionalismo (Kimmerling, 1992a; 2007a, pp. 7-10; 2008, pp. xii-xvi). Até então se definia defensor de uma ciência weberiana livre de valores, sionista, moderado quanto ao conflito árabeisraelense e liberal economicamente (Kimmerling, 1985, p. xviii).

3 Os trabalhistas esposaram um "sionismo prático", favorecendo a ocupação e a construção de instituições - com uma relação ambígua, entre abrangente e pragmática, com o território. Os revisionistas apostavam na acumulação de poder em geral e na ocupação de toda a Palestina. Desde o início militarizaram-se, o que apenas aos poucos ocorreu com o trabalhismo.

4 Ao falar da "falta de sensibilidade" das políticas originais sobre imigração, ele parece fazer certa autocrítica de sua perspectiva anterior, fortemente funcionalista e assimilacionista, ainda que bastante ciente das diferenças étnicas entre os judeus (Eisenstadt, 1954). Para uma visão ácida da questão étnica, da discriminação e da exploração dos sefaradins, ver Shohat, 1988.

5 Valorizando os Estados Unidos como uma colonização de povoamento (settler society), à qual se assemelharia muito Israel, inclusive no fervor ideológico dos "pioneiros", Eisenstadt (1992a) depois a contrastou com a colonização ibérica das Américas. Não apenas esquecia a situação do sul e dos negros norte-americanos como desconsiderava o genocídio a que foram submetidos os indígenas, o que é instrutivo dos limites de sua análise.

6 Com um funcionalismo também mais flexível, Horowitz e Lissak (1989) enfrentaram os problemas da crise ideológica, das demandas dos grupos cuja clivagem constituía a sociedade israelense, da relação com os árabes, da dominância asquenazim, dos imigrantes desfavorecidos. Com poucos recursos e baixa capacidade de regulação, o "centro" teria se enfraquecido. Apontaram ainda para o funcionamento de um "conjunto dual de normas" (soberania nas fronteiras formais de Israel, controle nos territórios ocupados), situação que oferecia a base para um Estado binacional.

7 Em seus primeiros textos sobre o tema Smooha fala de democracia de Herrenvolk, descartando essa classificação depois, uma vez que ali não haveria de fato democracia, devido ao poder absoluto de uma minoria. Segundo ele, para além das bordas de 1967, o estabelecimento da Autoridade Palestina em 1994 "prova[va] que Israel não se encaixava nessa classificação" (Smooha, 1997, p. 203). Curiosamente, não aparecem em seus trabalhos sobre a "democracia étnica" as questōes interétnicas entre sefaradins e asquenazins, tão importantes em análises anteriores pautadas por uma perspectiva "pluralista" (Smooha, 1978).

8 O conceito de "democracia consocional" refere-se basicamente a duas ou mais comunidades em grande medidas autogeridas que, contudo, compartilham um sistema político comum no âmbito federal, com representação proporcional.

9 Tese tão estreita cria limites para o argumento de Shafir. Mas, caso contrário, o autor se aproximaria muito dos argumentos de Horowitz e Lissak ([1977] 1978), que trataram o yishuv como uma realidade fechada que, inicialmente, se misturava com os palestinos, dos quais, por vários meios, buscaram separar-se os imigrantes judeus - exceto aqueles que empregavam a barata mão-de-obra local.

10 Embora Kimmerling faça uma crítica dura a Eisenstadt, a quem acusa de ideologização e mitologização (1992a; 2007a, pp. 7-9 e 11), seus textos compartilham várias das teses sociológicas do ex-professor que, por seu turno, não cita seus trabalhos sobre a colonização.

11 Para uma análise crítica da sociologia quanto à questão militar, ver Peri, 1996; na direção oposta, radicalizando a crítica, ver Grinberg, 2009, Parte 4.

\section{BIBLIOGRAFIA}

ALEXANDER, Jeffrey A. (1992), "The fragility of progress: an interpretation of the turn toward meaning in Eisenstadt's later work". Acta Sociologica, 35 .

AVNERI, Shlomo. (2007), "Post-Zionism doesn't exist". Haaretz, 6 jul.

BEN-PORA, Guy et al. (2008), Israel since 1980, Cambridge, Cambridge University Press.

BERNSTEIN, Richard. (1978), The restructuring of social and political theory. Philadelphia, University of Pennsylvania Press.

CYPEL, Sylvain. ([2005] 2006), Walled. Israeli society at an impasse. Nova York, The Other Press.

DOMINGUES, José Maurício. ([2000] 2003), "Criatividade e tendências mestras na teoria sociológica contemporânea”, in , Do 
ocidente à modernidade: intelectuais e mudança social, Rio de Janeiro, Civilização Brasileira. . (2002), Interpretando a modernidade: imaginário e instituiçôes. Rio de Janeiro, FGV. . (2009), "Latin America in comparative perspective". Theory, Culture \& Society, 26.

EISENSATDT, Shmuel N. (1954), The absorption of immigration: a comparative study based mainly on Jews in Palestine and the State of Israel. Londres, Routledge \& Kegan Paul.

. (1967), Israeli society: background, development and problems. Londres, Weinlfeld \& Nicolson.

. (1985), The transformation of Israeli society: an essay in interpretation. Londres, Weinfeld \& Nicolson.

. (1990), "Modes of structural differentiation, elite structure and cultural vision", in J. C. Alexander e P. Colomy (orgs.), Differentiation theory and social change, Nova York, Columbia University Press.

. (1992a), "Introduction", in M. Buber, On intersubjectivity and cultural creativity, Chicago, The University of Chicago Press.

. (1992b), "Culture, religions and development in North American and Latin American civilizations". International Social Science Journal, 134.

. (1995), "Jewish civilization: approaches to problems of Israeli society", in S. Deshe, C. Liebman e M. Shokeid (orgs.), Israeli Judaism: studies of Israeli society, New Brunswick, Transaction, vol. 7.

GAVISON, Ruth. (1999), "Jewish and democratic? A rejoinder to the 'ethnic democracy' debate". Israel Studies, 4.

GHANEM, As'ad. (1998), "State and minority in Israel: the case of ethnic state and the predicament of its minority". Ethnic and Racial Studies, 21.

. (2009), "The bi-national state solution". Israel Studies, 14.

GHANEM, As'ad, Rouhana, N. \& Yiftachel, O. (1998), "Questioning 'ethnic democracy': a response to Sammy Smooha”. Israel Studies, 3.

GRINBERB, Lev Luis. (2009), Politics and violence in Israel/Palestine. Londres, Routledge.
HAZONY, Yoram. (2000), The Jewish State: the struggle for Israel's soul. Nova York, Basic Books.

HOROWITZ, Dan \& Lissak, Moshe. ([1977] 1978), Origins of the Israeli Polity, Chicago, University of Chicago Press.

. (1989), Trouble in utopia: the overburdened polity of Israel, Albany, Suny Press.

KHALID, Rashid. (2006), The Iron Cage: the story of the Palestinian struggle for Statehood. Boston, Beacon.

KIMMERLING, Baruch. (1983), Zionism and territory: the socio-territorial dimensions of zionist politics. Berkeley, The University of California/ Institute of International Studies.

. (1985), The interrupted system: Israeli civilians in war and routine times. New Brunswick, Transaction.

. (1992), "Sociology, ideology, and nation-building: the Palestinians and their meaning in Israeli sociology”. American Sociological Review, 57.

. ([1992] 2008), "Patterns of militarism in Israel”, in _ Clash of identities: explorations in Israeli and Palestinian societies, Nova York, Columbia University Press.

. (2005), "The failure of Israeli academia and public sociologies: a call for discussion and debate". Israel Studies Forum, 20.

. (2007a), The invention and decline of Israeliness: State, society, and the military. Berkeley/Los Angeles, University of California Press.

. (2007b), "The exhaustion of the primary Zionist program: S. N. Eisenstadt between dynamic conservatism and critical perspectives". Archives Européennes de Sociologie, XLVIII.

. (2008), "Preface", in

Clash of identities: explorations in Israeli and Palestinian societies, Nova York, Columbia University Press.

KIMMERLING, B. \& Migdal, Joel S. (2003), The Palestinian people: a history. Cambridge, Harvard University Press.

LISSAK, Moshe. (1996), "'Critical' sociology and 'establishment' sociology in the Israeli acade- 
mic community: ideological struggles or academic discourse?". Israel Studies, 1.

MORRIS, Benny. (2009), One State, two States: resolving the Israel/Palestine conflict. New Haven, Yale University Press.

PERI, Yoram. (1996), "The radical social scientists and Israeli militarism". Israel Studies, 1.

RAM, Uri. (1995), The changing agenda of Israeli sociology: theory, ideology and identity. Albany, Suny Press.

. (2008), The globalization of Israel. McWorld in Tel Aviv, Jihad in Jerusalem. Londres, Routledge.

ROUANA, Nadim \& Ghanem, As'ad. ([1993] 1999), "The democratization of a traditional minority in an ethnic democracy: the Palestinian in Israel", in I. Pappé (org.), The Israell Palestine question (rewriting history), Londres, Routledge.

SHAFIR, Gershon. (1996a), Land, labor and the origins of Israeli-Palestinian conflict, 1882-1914. Chicago, University of Chicago Press. . (1996b), "Israeli society: a counterview". Israel Studies, 1.

SHAFIR, Gershon \& Pelev, Yoav. (1998), "Citizenship and stratification in an ethnic democracy". Ethnic and Racial Studies, 21. . (2002), Being Israeli: the dynamics of multiple citizenship. Cambridge, Cambridge University Press.

SHALEV, Michael. (1996), "Time for theory: critical notes on Lissak and Sternheel". Israel Studies, 1.

SHAPIRA, Anita \& Penslar, Derek J. (orgs.) (2002), Israeli historical revisionism: from left to right. Londres/Portland, Frank Cass.

SHAPIRO, Yonathan. (1984), "Political sociology in Israel: a critical view", in E. Krausz (org.), Politics and society in Israel: studies of Israeli society, New Brunswick, Transaction, vol. 3.

SHOHAT, Ella. (1988), "Sephardim in Israel: Zionism from the standpoint of its Jewish victims", Social Text, 19/20. . (1978), Israel: pluralism and conflict. Londres, Routledge \& Kegan Paul. (1997), "Ethnic democracy: Israel as an archetype". Israel Studies, 2.
. (2002a), "Types of democracy and modes of conflict management in ethnically divided societies". Nations and Nationalism, 8. . (2002b), "The model of ethnic democracy: Israel as a Jewish and democratic state". Nations and Nationalism, 8. (2005), "Is Israel Western?", in E. Ben-Rafael e I. Stern (orgs.), Comparing modernities: essays in hommage to Shmuel N. Eisenstadt, Leiden/Boston, Brill.

YIFTACHEL, Oren. (2006), Ethnocracy: land and identity politics in Israel/Palestine. Philadelphia, University of Pennsylvania Press. 


\section{A SOCIOLOGIA ISRAELENSE E A CRISE DO CONSENSO SIONISTA}

\section{José Maurício Domingues}

Palavras-chave: Israel; sionismo; colonização; democracia.

A sociedade israelense vem enfrentando uma crise do sionismo que esteve na base de sua constituição já há algumas décadas. Uma consistente produção sociológica, que remonta ao trabalho de Shmuel Eisenstadt, desdobrou-se paralelamente a essa crise, com ela interagindo de forma crítica. Isso se expressa nas discussões sobre o caráter da colonização judaica da palestina, nas obras de Kimmerling e Shafir, bem como no debate sobre a "democracia étnica” proposto por Smooha. Essas discussões são revistas aqui, conectando-se com as análises sobre a sociedade israelense hoje. A relação com os palestinos destaca-se em toda essa literatura e neste artigo, uma vez que em grande medida ela sobredetermina o conjunto dos processos sociais que caracterizam a sociedade israelense.

\section{ISRAELI SOCIOLOGY AND THE CRISIS OF THE ZIONIST CONSENSUS}

\section{José Maurício Domingues}

Keywords: Israel; Zionism; colonization; democracy.

The Israeli society has faced a crisis of the Zionism that has been the basis of their constitution for decades. A consistent sociological production dating back to the work of Shmuel Eisenstadt has unfolded in parallel with such crisis, having interacted with it in a critical way. This is expressed in discussions about the character of the Jewish colonization of Palestine in the works of Kimmerling and Shafir, as well as in the debate over the "ethnic democracy" proposed by Smooha. These discussions are herein reviewed in connection with analyses of the Israeli society today. The relationship with the Palestinians appears in both all the literature and this article, since it largely overdetermines all the social processes that have characterized the Israeli society.

\section{LA SOCIOLOGIE ISRAÉLIENNE ET LA CRISE DU CONSENSUS SIONISTE}

\section{José Maurício Domingues}

Mots-clés: Israël; sionisme; colonisation; démocratie.

La société israélienne affronte une crise du sionisme qui a été à la base de la constitution depuis déjà quelques décennies. Une production sociologique consistante, qui remonte au travail de Shmuel Eisenstadt, s'est déployée parallèlement à cette crise, tout en interagissant avec elle de façon critique. Cela s'expresse dans les discussions sur le caractère de la colonisation juive de la Palestine, dans les travaux de Kimmerling et de Shafir, ainsi que dans le débat sur la "démocratie ethnique” proposée par Smooha. Cet article repense ces discussions en connexion avec les analyses sur la société israélienne d'aujourd'hui. Le rapport avec les palestiniens est mis en évidence dans toute cette littérature et dans cet article, étant donné qu' elle surdétermine, en grande partie, l'ensemble des processus sociaux qui caractérisent la société israélienne. 